\title{
Standard Gibbs Free Energy Change
}

National Cancer Institute

\section{Source}

National Cancer Institute. Standard Gibbs Free Energy Change. NCI Thesaurus. Code C52567.

A measure of the spontaneity of a chemical reaction. It is the change in the free energy of a system during a chemical reaction at a $\mathrm{pH}$ of 7.0. It is equal to the change in the enthalpy of the system minus the change in the product of the temperature times the entropy of the system. The resulting sign of Delta $G$ determines if a reaction is spontaneous or not: DG $<0$ indicates that the reaction is spontaneous; DG $>0$ indicates that the reaction is not spontaneous; and DG $=0$ indicates that the reaction is at equilibrium. 